\title{
A calculadora HP 12C como facilitadora no processo de ensino de matemática financeira: uma revisão sistemática de literatura
}

\author{
The HP 12C calculator as a facilitator in the financial math teaching \\ process: a systematic literature review
}

\author{
Josiane Luiz (professorajosianeluiz@gmail.com) \\ Faculdades Cristo Rei (FACCREI) \\ Universidade Estadual do Norte do Paraná (UENP) \\ Willian Aparecido de Jesus Luditk (willianluditk@gmail.com) \\ Universidade Estadual do Norte do Paraná \\ João Coelho Neto (joaocoelho@uenp.edu.br) \\ Universidade Estadual do Norte do Paraná \\ Simone Luccas (simoneluccas@uenp.edu.br) \\ Universidade Estadual do Norte do Paraná
}

\section{Resumo:}

Este trabalho trata da utilização da tecnologia digital como um instrumento que pode conduzir o processo de ensino e ainda fazer com que os alunos se tornem consumidores mais conscientes e preparados para o mercado de trabalho. Neste contexto, esta pesquisa tem como objetivo mapear trabalhos que abordem a calculadora HP 12c como instrumento no processo de ensinar Matemática Financeira em todos os níveis de Ensino. O encaminhamento metodológico utilizado foi a Revisão Sistemática de Literatura, tendo como recorte de tempo os anos de 2009 a 2019 nos seguintes bancos de dados: BDTS e IBCT. Como resultado dos 1.671 trabalhos analisados, somente 14 tratavam da temática, caracterizando a utilização da calculadora HP 12c um instrumento para abordar os conteúdos de Matemática Financeira nos mais variados níveis de Ensino, levando a ganhos significativos quanto à Educação Financeira destes alunos.

Palavras-chave: Ensino; Tecnologia; Matemática Financeira; Revisão Sistemática de Literatura; Calculadora HP 12C.

\begin{abstract}
:
This paper deals with the use of digital technology as an instrument that can guide the teaching process and make students become more aware and prepared for the job market. In this context, this research aims to map papers that approach the HP $12 \mathrm{c}$ calculator as an instrument in the process of the Financial Mathematics teaching at all levels of education. The approach methodological used was the Systematic Literature Review, taking as a timeframe the years 2009 to 2019, in the following databases: BDTS and IBCT. As a result of the 1.671 papers was analyzed, only 14 dealt with the
\end{abstract}


theme, characterizing the use of the HP 12c calculator as a tool to approach the contents of Financial Mathematics, in the most varied levels of education, leading to significant gains regarding the financial education of these students.

Keywords: Teaching, Technology, Financial Mathematics, Systematic Literature Review; HP 12C calculator.

\section{INTRODUÇÃO}

Quando se reporta à temática que acomoda o caminho entre o ensinar e aprender, várias são as pesquisas e discussões a respeito de quais os possíveis recursos que podem ser adotados e utilizados por professores e alunos para que se consiga atingir os objetivos previamente pactuados pelos currículos competentes a cada nível de ensino, curso, disciplina e cada tendência metodológica aplicada à prática de ensinar.

Neste mesmo contexto, trabalhos como Caramari (2009), Falcão Neto (2011), Fortunato (2013), Simão (2013), Medeiros (2014), Oliveira (2014), Oliveira (2014), Pires (2014), Silva (2015), Martins (2016), Silva (2016), Amaral (2017), Luiz (2017) e Silva (2017), e utilizados nesta pesquisa, mostram a tecnologia digital como aliada no processo de ensino de Matemática, notadamente, abordando a Matemática Financeira a fim de contribuir para a construção do conhecimento.

Para Vannucci (2003), os cálculos matemáticos aplicados à esfera financeira tornaram-se mais rápidos e de fácil compreensão com a chegada das calculadoras financeiras, cujas funções foram desenvolvidas especificamente para esta área, deixando para trás o uso das planilhas e tabelas financeiras manuais. Esta evolução pode oportunizar ao aluno compreensões as quais vão além do proposto pelas bases curriculares, despertando o interesse por investigações matemáticas, pois quando o aluno investiga, procura algo que não conhece. Percorrendo o caminho da análise num contexto financeiro, os autores Ponte, Brocardo e Oliveira (2009) enunciaram que, além de observar o melhor caminho a ser percorrido pelo dinheiro ao longo do tempo, o resultado dessa investigação pode influenciar na tomada de decisão de um investimento, do consumo e, até mesmo, na hora de poupar. 
Levando em consideração que um dos objetivos da Matemática Financeira é formar cidadãos que saibam analisar criticamente as operações financeiras das quais fazem uso diariamente, Zabala (1998) indaga a respeito da finalidade do sistema educativo, destacando que, além de qualquer proposta metodológica, deve haver a valorização da potencialidade do aluno. Para o autor, o ensino deve ter função social, cabendo reflexão profunda da condição e cidadania dos alunos.

Dessa forma, cabe ao professor, em boa parte, tornar a sala de aula um ambiente atrativo, principalmente, para os jovens, desafiando os modelos existentes, incluindo recursos didáticos capazes de aproximar a sala de aula do mundo globalizado, incluindo tecnologias para esse processo, buscando sempre exercer a função social do ensino. Na visão de Vieira e Restivo (2014, p. 40), observa-se que:

mesmo com o risco de continuarmos a errar, temos de insistir na modernização do espaço de convívio escolar. Não devendo isolar a sala de aula do mundo tal como ele é visto pelo jovem, temos de criar estratégias de utilização das tecnologias para a aprendizagem ou, pelo menos, de compatibilização dessas tecnologias com alguma eficácia da aprendizagem.

Levando em consideração que a Matemática Financeira está presente diariamente na vida das pessoas e que, desde que usada adequadamente tem-se a tecnologia em favor do conhecimento, pensou-se em realizar uma Revisão Sistemática de Literatura (RSL) dos trabalhos publicados no Banco de Teses e Dissertações da Coordenação de Aperfeiçoamento de Pessoal de Nível Superior (CAPES) e na Biblioteca Digital Brasileira de Teses e Dissertações - BDTS - por meio do Instituto Brasileiro de Informação e Tecnologia - IBCT.

A pesquisa teve como recorte de tempo os anos de 2009 a 2019, cujo objetivo foi mapear trabalhos que abordem a calculadora HP 12c, para o ensino de Matemática Financeira. A busca foi à luz da Revisão Sistemática de Literatura, baseada em Kitchenham (2004) com o propósito de identificar de que forma a calculadora HP 12c está sendo utilizada no ensino de Matemática Financeira.

Para a construção deste artigo e a mensuração dos resultados indagados nos objetivos elencados, este trabalho foi dividido em quatro seções: a primeira contextualiza os motivos pelos quais a pesquisa foi realizada; a segunda seção apresenta 
os materiais e métodos; na terceira, a apresentação dos resultados e discussões e, na quarta e última seção, as considerações finais e perspectivas de trabalhos futuros.

\section{MATERIAIS E MÉTODOS}

Toda Revisão Sistemática de Literatura (RSL) deve ser realizada de acordo com um plano predefinido. Os passos metodológicos utilizados para este trabalho foram estruturados à luz das etapas da Revisão Sistemática da Literatura (RSL) baseado em Kitchenham (2004) a qual reúne trabalhos relevantes sobre uma questão formulada, utilizando banco de dados de literatura que trata daquela questão como fonte e métodos de identificação.

Esse tipo de investigação, por meio da revisão, tende a disponibilizar um resumo do destaque relacionado a uma estratégia de intervenção e busca sistematizada, sintetizando a informação selecionada. Para a construção de RSL, é importante que se descreva as etapas que constituem sua elaboração as quais foram definidas por Kitchenham (2004), conforme apresentado na sequência.

\section{QUESTÕES DA PESQUISA}

Esta RSL possui como questão primária da pesquisa a seguinte pergunta: De que forma a calculadora HP 12c está sendo utilizada no contexto de ensino? A fim de que fosse possível responder a essa pergunta, foram definidas as seguintes questões secundárias de pesquisa:

QP1: A Calculadora HP 12c vem sendo utilizada no processo de ensino de Matemática Financeira?

QP2: Quais são os ambientes de desenvolvimento e o público alvo que está sendo foco dos trabalhos de pesquisa relacionados ao ensino da Matemática Financeira?

QP3: Caso o aluno não possua a Calculadora HP 12c é possível o uso de algum aplicativo para ser instalado nos seus aparelhos celulares?

QP4: As pesquisas demonstram ganhos significativos no ensino quando da utilização desse instrumento? 
De acordo com os estudos de (PAI et al., 2004), as questões de pesquisa podem ser estruturadas seguindo o conjunto de critérios chamados de PICO - P (população a ser analisada, público alvo), I (intervenção), C (comparação) e O (resultados, do termo em inglês outcomes). Com base nesses critérios e com adaptação para a questão primária dessa pesquisa, o Quadro 1 apresenta os critérios PICO de investigação para esta RSL.

Quadro 1 - Critérios PICO para a questão primária da pesquisa.

\begin{tabular}{|l|l|}
\hline População & Trabalhos relacionados à temática nas bases selecionadas. \\
\hline Intervenção & Avaliação do uso da Calculadora HP 12c. \\
\hline Comparação & Processo de ensino com o uso da HP 12c. \\
\hline Resultados & Indicadores relacionados à questão primária. \\
\hline
\end{tabular}

Fonte: autores (2019)

Após a adaptação do conjunto de critérios PICO, observa-se então o caminho a ser seguido para que se obtenha um consenso na seleção dos estudos da literatura.

\section{IDENTIFICAÇÕES DE ESTUDOS, FONTE BUSCA, SELEÇÃO E CRITÉRIOS DE INCLUSÃO E EXCLUSÃO}

A pesquisa foi realizada por meio de busca manual no Banco de Teses e Dissertações da Coordenação de Aperfeiçoamento de Pessoal de Nível Superior (CAPES) e na Biblioteca Digital Brasileira de Teses e Dissertações - BDTS a partir do Instituto Brasileiro de Informação e Tecnologia - IBCT. A pesquisa teve como recorte de tempo os anos de 2009 a 2019, utilizando como critério de busca a palavra-chave "HP 12c". Em cada base de dados, a busca foi realizada em duas fases: a pré-seleção dos artigos constituiu-se em investigar as bases selecionadas e acessar manualmente todos os artigos completos, lendo os seus títulos, resumos e palavras-chave; na segunda fase, todos os artigos selecionados foram lidos integralmente, segundo os critérios de inclusão e exclusão, apresentados no Quadro 2. 
Quadro 2 - Critérios de Inclusão e Exclusão

\begin{tabular}{|c|c|}
\hline Critérios de Inclusão & Critérios de Exclusão \\
\hline $\begin{array}{l}\text { Trabalhos que abordem o uso da } \\
\text { calculadora HP } 12 \mathrm{c} \text { nos processos de } \\
\text { ensino e de aprendizagem de Matemática } \\
\text { Financeira. }\end{array}$ & $\begin{array}{l}\text { Trabalhos que tratam do ensino de } \\
\text { matemática financeira, mas não } \\
\text { utilizando a calculadora HP } 12 \mathrm{c} \text { como } \\
\text { instrumento. } \\
\text { Trabalhos que utilizam a calculadora HP } \\
\text { 12c para atividades não ligadas ao ensino } \\
\text { de Matemática Financeira. } \\
\text { Trabalhos repetidos nas duas bases de } \\
\text { busca. }\end{array}$ \\
\hline
\end{tabular}

Fonte: autores (2019)

Identificar os estudos incluindo-os e/ou excluindo-os é documentar a estratégia de como conduzir a busca pelos estudos relevantes podendo atender ao que apregoa as questões primárias e secundárias da pesquisa.

A partir da lista de artigos aferidos com o processo de busca nas bases, cada um deles foi lido para que fosse assegurada a pertinência quanto à temática da questão primária desta RSL, observando-se os critérios de inclusão e exclusão, bem como a relevância deste para o meio acadêmico.

Este trabalho segue norteado pelas questões de pesquisa elencadas no tópico 2.1. Para tal, o Quadro 3 apresenta a metodologia para a extração dos dados, observando que os trabalhos foram lidos e fichados para o melhor atendimento aos objetivos propostos.

Quadro 3 - Processo de extração dos dados

\begin{tabular}{|l|l|}
\hline P1 & $\begin{array}{l}\text { Observar se algum dos trabalhos incentiva o uso da calculadora HP 12c como } \\
\text { instrumento facilitador no processo de ensino e de aprendizagem. }\end{array}$ \\
\hline P2 & Identificar em quais níveis de ensino a temática se acomoda. \\
\hline P3 & $\begin{array}{l}\text { Aferir se em alguma das pesquisas há o uso de aplicativo da calculadora HP 12c } \\
\text { nos aparelhos celulares dos alunos. }\end{array}$ \\
\hline P4 & $\begin{array}{l}\text { Na leitura dos resultados da pesquisa, observar se a utilização da calculadora HP } \\
\text { 12c promove maior apropriação do conhecimento em Matemática Financeira. }\end{array}$ \\
\hline
\end{tabular}




\section{O PROCESSO DE AVALIAÇÃO DE QUALIDADE}

Segundo Kitchenham (2007), a qualidade de uma RSL depende da qualidade dos estudos primários incluídos. Desta forma, quanto mais criteriosa for a busca pelos trabalhos e mais ampla for sua avaliação, melhor será a qualidade do trabalho final. Segundo a autora, é importante criar questões de avaliação que devem estar imersas nas questões primárias e secundárias da pesquisa. Vejamos as questões de avaliação utilizadas neste estudo:

QA1: Os trabalhos apresentados podem promover o preparo de cidadãos tanto para a administração de suas próprias finanças quanto para o próprio mercado de trabalho?

QA2: O estudo avaliado incentiva professores de Matemática Financeira a utilizar a calculadora HP 12c como meio auxiliar de instrução no desenvolvimento do raciocínio do aluno?

QA3: Foi realizado algum tipo de estudo de caso como avaliação para o estudo da proposta?

QA4: O estudo avaliado foi aplicado em alguma escola/universidade?

QA5: O instrumento calculadora HP 12c foi visto como um meio acessível para o uso da tecnologia em sala de aula?

\section{RESULTADOS E DISCUSSÃO}

Inicialmente, a busca eletrônica foi feita no Banco de Teses e Dissertações da Coordenação de Aperfeiçoamento de Pessoal de Nível Superior (CAPES), sendo a palavra-chave inserida para busca "HP 12c", retornando 1.671 trabalhos. Sendo assim, pela leitura dos títulos dos trabalhos, foi identificado que somente 359 utilizavam a HP 12c para ensinar Matemática Financeira.

A partir deste momento, foram lidos todos os abstracts desta amostra de 359 títulos, aplicando-se os critérios de inclusão e exclusão conforme o disposto no Quadro 2. Isto posto, observando os critérios de avaliação estabelecidos no item 2.3 deste 
trabalho, e o processo para extração dos dados, a amostra extraída para a leitura integral se dá no montante de 14 trabalhos. Para melhor visualizar o panorama de resultados, o Quadro 4 foi elaborado, demonstrando os dados da seguinte forma:

Quadro 4 - Trabalhos: Teses e Dissertações da CAPES

\begin{tabular}{|c|c|c|c|c|}
\hline $\mathbf{N}^{\mathbf{o}}$ & Título do Trabalho de Pesquisa & Autor/Ano & $\begin{array}{l}\text { Programa } \\
\text { de Pesquisa }\end{array}$ & $\begin{array}{c}\text { Nível de } \\
\text { Aplicação } \\
\text { da Pesquisa }\end{array}$ \\
\hline 1. & $\begin{array}{l}\text { O Estudo de Tópicos de } \\
\text { Matemática Financeira com } \\
\text { Tecnologias Informáticas: } \\
\text { Opiniões de Professores } \\
\text { Participantes de um Grupo de } \\
\text { Formação Continuada }\end{array}$ & $\begin{array}{l}\text { Fátima } \\
\text { Merielen } \\
\text { Caramori } \\
(2009)\end{array}$ & $\begin{array}{l}\text { PEFM/UNI } \\
\text { FRA }\end{array}$ & $\begin{array}{l}\text { Curso } \\
\text { Técnico/Prof } \\
\text { issionalizante }\end{array}$ \\
\hline 2. & $\begin{array}{l}\text { O uso da Calculadora HP } 12 \mathrm{C} \text { nas } \\
\text { Operações de Matemática } \\
\text { Financeira Comercial com Ênfase } \\
\text { na Análise de Investimentos }\end{array}$ & $\begin{array}{l}\text { Antonio } \\
\text { Falcão Neto } \\
\text { (2011) }\end{array}$ & $\begin{array}{l}\text { PROFMAT/ } \\
\text { UFC }\end{array}$ & $\begin{array}{l}\text { Curso } \\
\text { Técnico/Prof } \\
\text { issionalizante }\end{array}$ \\
\hline 3. & $\begin{array}{c}\text { A Utilização da Calculadora HP- } \\
\text { 12C no Ensino da Matemática } \\
\text { Financeira Visando a Qualificação } \\
\text { Profissional }\end{array}$ & $\begin{array}{l}\text { Júnior Cezar } \\
\text { Mendes Simão } \\
\text { (2013) }\end{array}$ & $\begin{array}{l}\text { PROFMAT/ } \\
\text { UFG }\end{array}$ & $\begin{array}{l}\text { Curso } \\
\text { Técnico/Prof } \\
\text { issionalizante }\end{array}$ \\
\hline 4. & $\begin{array}{c}\text { Matemática Financeira, Sistemas } \\
\text { de Amortização e Empréstimos: } \\
\text { Uma Proposta Prática com a com } \\
\text { a Calculadora HP } 12 \mathrm{C}\end{array}$ & $\begin{array}{l}\text { Silvério } \\
\text { Fortunato } \\
\text { (2013) }\end{array}$ & $\begin{array}{l}\text { PPGENCT/ } \\
\text { URIRS }\end{array}$ & $\begin{array}{l}\text { Ensino } \\
\text { Superior }\end{array}$ \\
\hline 5. & $\begin{array}{l}\text { A Utilização da Matemática na } \\
\text { Educação Financeira no Ensino } \\
\text { Médio } \\
\end{array}$ & $\begin{array}{c}\text { João Luiz da } \\
\text { Silva Medeiros } \\
(2014) \\
\end{array}$ & $\begin{array}{l}\text { PROFMAT/ } \\
\text { URFJ }\end{array}$ & $\begin{array}{l}\text { Ensino } \\
\text { Médio }\end{array}$ \\
\hline 6. & $\begin{array}{l}\text { O Ensino da Matemática } \\
\text { Financeira utilizando a } \\
\text { Calculadora HP 12C }\end{array}$ & $\begin{array}{c}\text { Mayana } \\
\text { Cybele Dantas } \\
\text { de Oliveira } \\
(2014 \mathrm{a})\end{array}$ & $\begin{array}{l}\text { PROFMAT/ } \\
\text { UFPB }\end{array}$ & $\begin{array}{l}\text { Ensino } \\
\text { Fundamental } \\
\text { e Médio }\end{array}$ \\
\hline 7. & $\begin{array}{l}\text { Série de Pagamentos: Uma } \\
\text { Aplicação da Matemática } \\
\text { Financeira no Ensino Médio }\end{array}$ & $\begin{array}{l}\text { Rodrigo de } \\
\text { Oliveira } \\
(2014 \mathrm{~b}) \\
\end{array}$ & $\begin{array}{l}\text { PROFMAT/ } \\
\text { UEM }\end{array}$ & $\begin{array}{l}\text { Ensino } \\
\text { Médio }\end{array}$ \\
\hline 8. & $\begin{array}{l}\text { Matemática Financeira para o } \\
\text { Ensino Médio }\end{array}$ & $\begin{array}{l}\text { Sandra Pires } \\
\text { (2014) }\end{array}$ & $\begin{array}{l}\text { PROFMAT/ } \\
\text { UFABC }\end{array}$ & $\begin{array}{l}\text { Ensino } \\
\text { Médio }\end{array}$ \\
\hline 9. & $\begin{array}{l}\text { A importância da Matemática } \\
\text { Financeira no Ensino Básico }\end{array}$ & $\begin{array}{l}\text { Alex Fabiano } \\
\text { Metello Silva } \\
(2015)\end{array}$ & $\begin{array}{l}\text { PROFMAT/ } \\
\text { IMPA }\end{array}$ & $\begin{array}{c}\text { Ensino } \\
\text { Fundamental }\end{array}$ \\
\hline 10. & $\begin{array}{l}\text { Introdução à Matemática } \\
\text { Financeira }\end{array}$ & $\begin{array}{c}\text { Adriano } \\
\text { Urbansk da } \\
\text { Silva }\end{array}$ & $\begin{array}{l}\text { INMA/UF } \\
\text { MS }\end{array}$ & $\begin{array}{l}\text { Ensino } \\
\text { Superior }\end{array}$ \\
\hline
\end{tabular}




\begin{tabular}{|c|c|c|c|c|}
\hline & & (2016) & & \\
\hline 11. & $\begin{array}{c}\text { A Utilização de Práticas } \\
\text { Pedagógicas Diferenciadas no } \\
\text { Ensino de Matemática Financeira: } \\
\text { Um Estudo de Caso no Instituto } \\
\text { Maranhense de Ensino e Cultura - } \\
\text { IMEC }\end{array}$ & $\begin{array}{l}\text { Iomara de } \\
\text { Albuquerque } \\
\text { Madeira } \\
\text { Martins } \\
\text { (2016) }\end{array}$ & $\begin{array}{l}\text { Ensino de } \\
\text { Ciências } \\
\text { Exatas/FUV } \\
\text { ATES }\end{array}$ & $\begin{array}{l}\text { Ensino } \\
\text { Superior }\end{array}$ \\
\hline 12. & $\begin{array}{c}\text { A Utilização da Calculadora HP } \\
\text { 12C em Problemas de Matemática } \\
\text { Financeira }\end{array}$ & $\begin{array}{l}\text { Josenildo } \\
\text { Rodrigues da } \\
\text { Silva } \\
(2017) \\
\end{array}$ & $\begin{array}{c}\text { PROFMAT/ } \\
\text { UFA }\end{array}$ & $\begin{array}{l}\text { Ensino } \\
\text { Fundamental } \\
\text { e Médio }\end{array}$ \\
\hline 13. & $\begin{array}{l}\text { Calculadora Financeira HP - 12C } \\
\text { em Smartphones como Recurso } \\
\text { Didático para o Ensino de } \\
\text { Matemática Financeira no Ensino } \\
\text { Médio }\end{array}$ & $\begin{array}{l}\text { Gordiano } \\
\text { Santana } \\
\text { Amaral } \\
(2017)\end{array}$ & $\begin{array}{c}\text { PROFMAT/ } \\
\text { UFOP }\end{array}$ & $\begin{array}{l}\text { Ensino } \\
\text { Médio }\end{array}$ \\
\hline 14. & $\begin{array}{l}\text { Proposta de um Livro Didático } \\
\text { com Recursos de Vídeo Aulas e } \\
\text { Calculadora HP 12C para o } \\
\text { Ensino de Matemática Financeira } \\
\text { nos Cursos Técnicos a Distância }\end{array}$ & $\begin{array}{l}\text { Katson Gerson } \\
\text { Teixeira da } \\
\text { Luz } \\
(2017)\end{array}$ & $\begin{array}{l}\text { PROFMAT/ } \\
\text { UFAC }\end{array}$ & $\begin{array}{c}\text { Curso } \\
\text { Técnico/Prof } \\
\text { issionalizante }\end{array}$ \\
\hline
\end{tabular}

Fonte: autores (2019)

Baseando-se nos dados apresentados pelo Quadro 4, dos 359 trabalhos inicialmente selecionados, cerca de 3,9\% abordavam a temática relacionada ao estudo primário desta RSL, que se trata da utilização da calculadora financeira HP 12c como ferramenta no ensino de Matemática Financeira. Abaixo, o Quadro 5 relaciona o processo de extração de dados disposto no Quadro 3 com os trabalhos encontrados:

Quadro 5- Relação processo de extração de dados versus trabalhos encontrados

\begin{tabular}{|l|l|}
\hline Processo de Extração de dados & Trabalhos Encontrados \\
\hline $\begin{array}{l}\text { P1- Observar se algum dos trabalhos } \\
\text { incentiva o uso da calculadora HP 12c como } \\
\text { instrumento facilitador no processo de } \\
\text { ensino e de aprendizagem. }\end{array}$ & $\begin{array}{l}\text { Todos os trabalhos utilizam a } \\
\text { calculadora HP 12C como instrumento } \\
\text { no processo de ensino de Matemática } \\
\text { Financeira }\end{array}$ \\
\hline $\begin{array}{l}\text { P2- Identificar em quais níveis de ensino a } \\
\text { temática se acomoda. }\end{array}$ & $\begin{array}{l}\text { Fundamental e Médio. } \\
3 \text { Trabalhos no Ensino Superior } \\
4 \text { Trabalhos no Ensino Técnico e } \\
\text { Profissionalizante }\end{array}$ \\
\hline $\begin{array}{l}\text { P3- Aferir se em alguma das pesquisas há o } \\
\text { uso de aplicativo da calculadora HP 12c nos } \\
\text { aparelhos celulares dos alunos. }\end{array}$ & 1 Trabalho \\
\hline
\end{tabular}


P4- Na leitura dos resultados da pesquisa, Todos os trabalhos apresentam em seus observar se a utilização da calculadora HP resultados ganhos na apropriação do 12c promove maior apropriação do conteúdo quando da utilização da conhecimento em Matemática Financeira. calculadora HP 12C.

Fonte: autores (2019)

Agora, quanto ao processo de avalição de qualidade dos trabalhos pesquisados, o Quadro 6 também relaciona este com os resultados da pesquisa:

Quadro 6- Processo de avalição de qualidade dos trabalhos versus trabalhos encontrados

\section{Processo de Avaliação de Qualidade}

QA1- Os trabalhos apresentados podem promover o preparo de cidadãos tanto para a administração de suas próprias finanças quanto para o próprio mercado de trabalho?

QA2- O estudo avaliado incentiva professores de Matemática Financeira a utilizar da calculadora HP 12c como meio auxiliar de instrução no desenvolvimento do raciocínio do aluno?

QA3- Foi realizado algum tipo de estudo de caso como avaliação para o estudo da proposta?

QA4- $O$ estudo avaliado foi aplicado em alguma escola/universidade?

QA5- O instrumento calculadora HP 12c foi visto como um meio acessível para o uso da tecnologia em sala de aula?

Trabalhos Encontrados

14 trabalhos

14 trabalhos

14 trabalhos

14 trabalhos

14 trabalhos

Fonte: autores (2019)

Observe na sequência a análise de alguns trabalhos citados no Quadro 4.

De acordo com o trabalho de Simão (2013), ensinar Matemática Financeira, utilizando como ferramenta a calculadora HP 12c, pode contribuir para tornar os alunos aptos a resolver situações financeiras cotidianas e ainda prepará-los não somente para o meio acadêmico, mas também para a administração de suas próprias finanças e a inclusão no mercado de trabalho. Analisando este trabalho, pode-se identificar que a proposta pedagógica aqui apresentada se dá em resolver em sala de aula situações do dia a dia que envolvam Matemática Financeira, através de encartes fornecidos por algumas lojas.

Munidos deste material, os alunos extraem todas as informações possíveis para que possa, por meio da calculadora HP 12c, encontrar algumas variáveis como taxa de juros, valor da parcela e montante pago no final do parcelamento. Este trabalho torna-se 
relevante, pois o aluno que possui esse tipo de preparação em sua vivência acadêmica, dificilmente será enganado no direito de exercício como consumidor e, até mesmo, em sua carreira profissional. A calculadora HP 12c aqui é utilizada para agilizar esse processo, pensando realmente no dia a dia desse aluno.

Todavia, na análise do trabalho de Silva (2015), observa-se sua expressa proposição para que seja feita a inclusão no currículo da educação básica a disciplina de Matemática Financeira. Argumenta tal proposta pelo fato da necessidade de serem criados alunos críticos, aptos à tomada de decisões e, consequentemente, consumidores mais conscientes, sabendo ao menos as possíveis vantagens e desvantagens de realizar compras à vista ou a prazo, assim como o impacto disso em seu orçamento.

O autor considera ainda que o maior desafio existente é a quebra de paradigma quanto à Matemática Financeira, tanto para os alunos quanto para os professores, que é o de transformar um monte de números e fórmulas em conhecimentos com significado. Para tanto, enfatiza que utilizar a tecnologia digital, assim como a calculadora HP 12c, pode facilitar esse processo. Ou seja, aqui a calculadora HP 12c é utilizada como um instrumento facilitador na resolução dos problemas.

Ao falar dos recursos didáticos e tecnológicos dos professores, Amaral (2017) diz que nos últimos anos há uma gama grande de produtos que possam ser utilizados para facilitar o processo de ensino, e claro, isso não seria diferente para a Matemática Financeira. Argumenta que a calculadora HP 12c entra em cena para contribuir com o processo, podendo ser utilizada por meio de um aplicativo instalado nos aparelhos celulares dos alunos, caso estes não tenham a ferramenta. Ou seja, não há desculpas. Estudar a inserção do uso do aplicativo no ensino de Matemática Financeira gerando possibilidades de ensino alternativo, capazes de ajudar até mesmo na inclusão digital, passou a ser também objeto de estudo.

Os resultados demonstram que o uso do aplicativo da calculadora HP 12c contribui significativamente para o ensino do conteúdo e que este pode ser uma boa ferramenta pedagógica, desmistificando a recusa irrestrita de smartphones e congêneres em sala de aula, requerendo apenas dos professores habilidades com o uso do aplicativo e uma boa compreensão sobre o momento oportuno para utilizar esse recurso. 
Desse modo, de acordo com os resultados da pesquisa de Martins (2016), ser professor está diretamente ligado a ser um profissional inovador, e inovar demanda tempo e dedicação, utilizando de práticas pedagógicas diferenciadas com o objetivo de poder alcançar a aprendizagem dos alunos, especialmente quando se fala em Matemática Financeira. O trabalho demonstrou que, quando a sociedade está preparada para consumir de forma consciente, possui a capacidade cognitiva de avaliar o processo de compra e de venda, quanto de juros que estão dispostos e preparados a pagar e ainda há coerências entre o valor dos produtos nas propagandas e o valor efetivamente aplicado.

A pesquisa demonstrou também que os alunos envolvidos nessa pesquisa tiveram melhores resultados quando utilizaram como instrumento a calculadora HP 12c. Fortunato (2013) explica que sua pesquisa serviu para coletar a opinião de estudantes frente à utilização da calculadora HP 12c no ensino de Matemática Financeira e no mercado de trabalho. Olhando pelo lado prático do ensino, essa pesquisa é válida, uma vez que a calculadora pode facilitar o processo, principalmente, quando for utilizada no mercado de trabalho.

Obviamente, não haverá tempo hábil para que profissionais construam modelos, analisem e interpretem fórmulas na frente de um cliente, na fila de um banco, ou até mesmo numa mesa de negociação. Aperfeiçoar o tempo com resultado é o que o mercado espera, e nesse contexto a calculadora HP 12c faz um grande trabalho. Para tanto, os alunos consideraram a ferramenta importantíssima para o estudo, bem como para o processo de tomada de decisões. Falando das possíveis soluções para problemas financeiros, Silva (2016) coloca em seu trabalho que utilizar de tecnologia para o ensino de Matemática Financeira pode contribuir para o sucesso da operação.

Afirma ainda que conceitos simples como juros, sistemas de amortização, cálculos de valores presentes e futuros de uma renda, podem ser didaticamente feitos com o auxílio de uma calculadora HP 12c. O trabalho deixa claro que não é necessário complicar a resolução de um problema matemático, muito pelo contrário. O que faz muitas vezes um aluno não gostar de certo conteúdo, é justamente o não entendimento dele, a dificuldade e complexidade de sua resolução. 
As ferramentas digitais utilizadas servem justamente para amenizar esse processo tornando-o menos complicado e demorado. Enfatizando ainda a importância de utilizar instrumentos no processo de ensino de Matemática Financeira, na análise do trabalho de Oliveira (2014), pode-se constatar que existe uma atribuição a certos conteúdos de Matemática Financeira por ser assuntos indispensáveis e de suma importância para a tomada de decisões e análise econômica e, é sobre estes, que devem pesar a inserção de ferramentas dinâmicas para ensinar. O autor atribui à calculadora HP 12c o papel de facilitar a resolução de problemas cotidianos e ressaltar que o que vale realmente aprender são aqueles conteúdos que são utilizados no dia a dia, seja pessoal, seja profissional, sendo essencial para habilitar o aluno ao exercício da cidadania.

Dentre as informações investigadas até aqui e demonstradas por meio de tabelas, relatamos aquelas que buscam responder a QP1: Como a Calculadora HP 12c vem sendo utilizada no processo de ensino de Matemática Financeira? Após a análise dos trabalhos, identificou-se que $100 \%$ da amostra utiliza a calculadora como um instrumento facilitador no processo de resolução de problemas relacionados à Matemática Financeira. Em meio às várias justificativas para o uso, formar consumidores mais conscientes e profissionais aptos ao desenvolvimento das atividades foram as que mais se destacaram, sempre reiterando que o uso da HP 12c pode auxiliar o processo, tornando-o mais fácil e atraente.

Assim, abordando a pesquisa à luz da argumentação da QP2: Quais são os ambientes de desenvolvimento e o público alvo que está sendo o foco dos trabalhos de pesquisa? Percebeu-se com a leitura da amostra dos trabalhos que 7,14\% destes abordam a temática no Ensino Fundamental; 28,57\% aplicaram sua pesquisa voltada ao Ensino Médio; 14,28\% trabalharam tanto com o Ensino Fundamental quando o Ensino Médio; 28,57\% trataram do Ensino Técnico e Profissionalizante e apenas 21,44\% apontam suas pesquisas no ensino superior.

Reportando a pesquisa para a possibilidade de utilização de um aplicativo da calculadora HP 12c nos aparelhos celulares dos alunos por meio de um software gratuito, a QP3: Caso o aluno não possua a Calculadora HP 12c é possível o uso de algum aplicativo para ser instalado nos seus aparelhos celulares? Dada a pesquisa, 
constatou-se que apenas $7,14 \%$ dos trabalhos utilizam-se de um aplicativo da calculadora HP 12c instalado nos aparelhos celulares dos alunos, ressaltando que sua aplicação se dá no Ensino Médio.

Por fim, dada a QP4: As pesquisas demonstram ganhos significativos no ensino quando da utilização desse instrumento? Em resposta a esta indagação, 100\% da amostra apontaram que, quando do uso do instrumento calculadora HP 12c no ensino de Matemática Financeira, os alunos podem contextualizar situações financeiras cotidianas, contribuindo significativamente para o desenvolvimento de consumidores conscientes, aptos à tomada de decisão.

Em síntese, fica bem claro que os trabalhos aferidos nesta plataforma de busca trazem a mesma preocupação das indagações primárias e secundárias desta RSL, que é a possibilidade de incluir ferramentas e auxílios pedagógicos no ensino da Matemática Financeira, não somente com propósito didático, mas como inclusão digital e, sobretudo, função social. Quando se falam em função social é no sentido de capacitar os alunos a serem consumidores conscientes, tomando decisões adequadas quanto à compra e venda de bens e serviços, sabendo assim administrar suas próprias finanças e de forma simples e ágil, utilizando a calculadora HP 12c.

Para a segunda parte desta pesquisa, foi utilizada a base da Biblioteca Digital Brasileira de Teses e Dissertações - BDTS por meio do Instituto Brasileiro de Informação e Tecnologia - IBCT que, utilizando dos mesmos critérios de busca e palavras-chave, retornou exatamente o mesmo resultado da base anterior, ou seja, 14 trabalhos que tratam da utilização a calculadora HP 12c como instrumento do ensino de Matemática Financeira. Conforme os critérios de exclusão elencados no Quadro 2, trabalhos repetidos não serão apresentados.

\section{CONSIDERAÇÕES FINAIS}

Com a pesquisa realizada à luz desta Revisão Sistemática de Literatura, foi possível perceber que é possível ensinar Matemática Financeira utilizando de recursos pedagógicos e ferramentas digitais que possam contribuir para o processo de ensino. No 
entanto, embora tenha sido pesquisado em duas grandes bases que acomodam teses e dissertações, poucas são as pesquisas que abordam essa temática, demonstrando o quanto é importante trazer estudos relevantes sobre.

Portanto, o estudo desenvolvido por esta Revisão Sistemática de Literatura fez um levantamento de trabalhos que abordam o ensino de Matemática Financeira, utilizando como instrumento a Calculadora HP 12c e a contribuição disso para o processo de ensino e a formação de consumidores conscientes e cidadãos preparados para a análise de situações financeiras cotidianas. Neste contexto, para encaminhamentos futuros, pretende-se desenvolver uma sequência didática a fim de auxiliar nesse processo, inclusive revisando outras bases de pesquisa, como em artigos e periódicos, já que esta foi apenas uma etapa do trabalho.

\section{REFERÊNCIAS}

ALMEIDA, Jarbas Thaunahy Santos de. Matemática financeira. Rio de Janeiro: LTC, 2016.

AMARAL, Gordiano Santana. Calculadora Financeira HP - 12C em Smartphones como Recuso Didático para o Ensino de Matemática Financeira no Ensino Médio. 2017. 97 f. Dissertação (Mestrado Profissional em Matemática) - Universidade Federal do Oeste do Pará, Santarém, 2017.

BLANCHARD, Olivier. Macroeconomia. São Paulo: Campus, 1999.

CAPES. Banco de Teses e Dissertações Tabela de áreas do conhecimento. 2014.

Disponível em http://bancodeteses.capes.gov.br/banco-teses. Acesso em 18 fev. 2019.

CARAMORI, Merielen Fátima. O estudo de tópicos de matemática financeira com tecnologias informáticas: opiniões de professores participantes de um grupo de formação continuada. 2009. 110 f. Dissertação (Mestrado Profissional em Ensino de Física e Matemática) - Centro Universitário Franciscano de Santa Maria, Santa Maria, 2009.

FORTUNATO, Silvério. Matemática Financeira, Sistemas de Amortização e

Empréstimos: Uma Proposta Prática com a com a Calculadora HP 12C. 2013. 122 f. Dissertação (Mestrado em Ensino Cientifico e Tecnológico) - Universidade Regional Integrada do Alto do Uruguai e das Missões, Rio Grande do Sul, 2013. 
KITCHENHAM, Barbara. A. Procedures for Performing Systematic Reviews. Tech. Report TR/SE- 0401, Keele University, 2004.

LUZ, Katson Roger Teixeira da. Proposta de um livro didático com recursos de videoaulas e calculadora HP 12C para o ensino de Matemática Financeira nos cursos técnicos a distância. 2017. 95 f. Dissertação (Mestrado Profissional em Matemática) - Universidade Federal do Acre, Rio Branco, 2017.

MARTINS, Iomara de Albuquerque Madeira. Utilização de práticas pedagógicas diferenciadas no ensino de matemática financeira: um estudo de caso no instituto maranhense de ensino e cultura - IMEC. 2016. 151 f. Dissertação (Mestrado em ensino de ciências exatas) - Centro Universitário UNIVATES, Lajeado, 2016.

MEDEIROS, João Luiz da Silva. A utilização da Matemática na educação Financeira no Ensino Médio. 2016. 120 f. Dissertação (Mestrado Profissional em Matemática) - Universidade Federal do Estado do Rio de Janeiro, Rio de Janeiro, 2016.

FALCÃO NETO, Antonio. O uso da calculadora HP 12C nas operações de Matemática Financeira comercial com ênfase na análise de investimentos. 2011. 134 f. Dissertação (Mestrado Profissional em Ensino de Ciências e Matemática) Universidade Federal do Ceará, Fortaleza, 2011.

OLIVEIRA, Mayana Cybele Dantas de. O Ensino da Matemática Utilizando a Calculadora HP 12C. 2014. 82 f. Dissertação (Mestrado Profissional em Matemática) - Universidade Federal da Paraíba, João Pessoa, 2014a.

PAI, Madhukar et al. Systematic reviews and meta-analyses: an illustrated, step-by-step guide. The National medical journal of India, v. 17, n. 2, p. 86-95, 2004.

SILVA, Alex Fabiano Metello. A importância da Matemática Financeira no Ensino Básico. 2015. 149 f. Dissertação de Mestrado. (Mestrado em Ensino) Instituto de Matemática Pura e Aplicada, Rio de janeiro, 2015.

PONTE, J. P. da; BROCARDO, J; OLIVEIRA, H. Investigações matemáticas na sala de aula. Belo Horizonte: Autêntica editora, 2009 (Coleção Tendências em Educação Matemática, 7)

SILVA, Josenildo Rodrigues da. A utilização da calculadora HP 12C em problemas de Matemática Financeira. 2017. 78 f. Dissertação (Mestrado Profissional em Matemática) - Universidade Federal de Alagoas, Maceió, 2017.

SIMÃO, Júnio César Mendes. A Utilização da Calculadora HP-12C no Ensino da Matemática Financeira Visando a Qualificação Profissional. 2013. 63 f. Dissertação (Mestrado Profissional em Matemática) - Universidade Federal de Goiás, Goiânia, 2013.

VANUCCI, Luiz Roberto. Cálculos Financeiros Aplicados e Avaliação Econômica de Projetos de Investimentos. São Paulo: Texto Novo, 2003.

VIEIRA, Fatima; RESTIVO, Maria Teresa. Novas Tecnologias e educação: ensinar a aprender/aprender a ensinar. Porto: Biblioteca Digital da Faculdade de Letras da 
universidade do Porto, 2014. Disponível em:

http://ler.letras.up.pt/uploads/ficheiros/13021.pdf. Acesso em: 25 fev. 2019.

ZABALA, Antoni. A Prática Educativa: como ensinar. Tradução Ernani F. da F. Rosa. Porto Alegre: ARTMED, 1998. 